
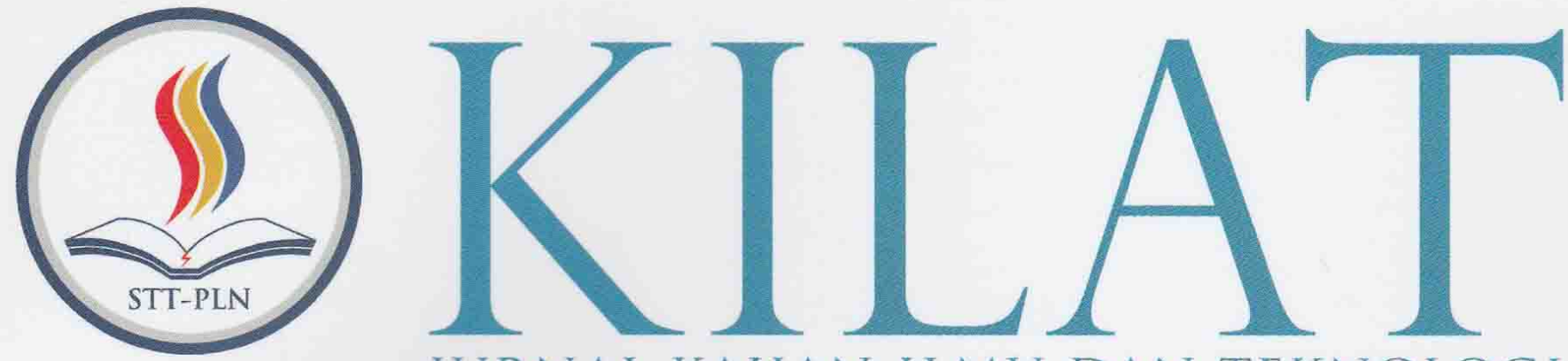

JURNAL KAJIAN ILMU DAN TEKNOLOGI

Endah Lestari: Irma Wirantina K: Ranti Hidayawanti

Faisal:

Muhammad Ridwan: Mardawati

Gita Puspa Artiani: Indah Handayasari

Kresna Ramanda; Irmawati Carolina

Ratna Mutu Manikam:

Farid Setiawan

Rayung Wulan

Roni Kartika Pramuyanti

Rr. Mekar Ageng Kinasti; Djoko Nugroho Notodisuryo

Satria;

Ayu Setiawati Agustini

Syam Gunawan: Pritasari Palupiningsih

Ali Ridho Gumelar: Anton: Ummu Radiyah

M. Yoga Distra Sudirman: Yessy Fitriani
ANALISA TAMAN ATAP DALAM UPAYA MENGURANGI LIMPASAN AIR HUJAN PADA BANGUNAN PERKOTAAN

OPTIMASI DIAGRAM LAYANAN PEMBELIAN DALAM MENDUKUNG MANAJEMEN HUBUNGAN PELANGGAN

OPTIMALISASI PENGOLAHAN SAMPAH ORGANIK DENGAN TEKNOLOGI BIODIGESTER SEBAGAI UPAYA KONSERVASI LINGKUNGAN

SELEKSI FITUR ALGORITMA NEURAL NETWORK MENGGUNAKAN PARTICLE SWARM OPTIMIZATION UNTUK MEMPREDIKSI KELAHIRAN PREMATUR

RANCANG BANGUN MEDIA BELAJAR FISIKA DASAR UNTUK MAHASISWA BERBASIS ANDROID

ANALISIS GLOBAL POSITIONING INFRASTRUKTUR DAN JARINGAN SOSIAL MEDIA DALAM BISNIS APLIKASI TRANSPORTASI DARAT ONLINE DI JAKARTA

PENGARUH INOVASI ANTENA PADA SIARAN TELEVISI MOBIL

PEMANFAATAN LIMBAH PEMBAKARAN BATUBARA (BOTTOM ASH) PADA PLTU SURALAYA SEBAGAI MEDIA TANAM DALAM UPAYA MENGURANGI PENCEMARAN LINGKUNGAN

PENERAPAN METODE GRAPHIC RATING SCALE (GRS) DALAM PENILAIAN KINERJA KARYAWAN

PEMBENTUKAN MODEL KLASIFIKASI DATA LAMA STUDI MAHASISWA STMIK INDONESIA MENGGUNAKAN DECISION TREE DENGAN ALGORITMA NBTREE

IMPLEMENTASI LOAD BALANCING DENGAN ALGORITMA EQUAL COST MULTI PATH (ECMP)

RANCANGAN SISTEM PENILAIAN HASIL KINERJA MULTI COMPANY DAN CROSS BUSINESS SECTOR 


\title{
RANCANG BANGUN MEDIA BELAJAR FISIKA DASAR UNTUK MAHASISWA BERBASIS ANDROID
}

\author{
Ratna Mutu Manikam ${ }^{1}$, Farid Setiawan ${ }^{2}$ \\ Program Studi Sistem Informasi, Fakultas IImu Komputer, Universitas Mercu Buana \\ Jl. Raya Meruya Selatan, Kembangan, Jakarta 11650 \\ e-mail : ratna_mutumanikam@mercubuana.ac.id ${ }^{1}, 41813010083 @ m e r c u b u a n a . a c . i d^{2}$
}

\begin{abstract}
ABSTRAK
Rancang bangun media belajar fisika dasar bertujuan membantu mahasiswa dalam memahami pelajaran fisika bagi mahasiswa khususnya dan masyarakat umum.. Rancangan ini berisikan rumus-rumus dasar fisika, latihan soal dan kasus yang berjalan dengan sistem operasi Android yang dirancang khusus untuk smartphone dan tablet, serta dapat dilakukan secara offline, sehingga pengguna tidak wajib terhubung pada internet untuk menggunakannya. Metode Rapid Application Design sangat baik digunakan untuk menyelesaikan masalah kesalahpahaman antara user dan analis yang timbul akibat user tidak mampu mendefinisikan secara jelas kebutuhannya. Serta analisanya menggunakan metode Unified Modeling Language digunakan untuk melakukan spesifikasi, visualisasi, konstruksi, dan dokumentasi artifak sebuah sistem perangkat lunak
\end{abstract}

Kata Kunci : Android, fisika, rumus

\section{ABSTRACT}

The design of basic physics aims to assist students in understanding the lessons of physics for students in particular and the general public .. This design contains basic formulas of physics, exercise problems and cases that run with the Android operating system designed specifically for smartphones and tablets, and can be done in offline, so users are not required to connect to the internet to use it. Rapid Application Design method is very well used to solve the problem of misunderstanding between users and analysts arising from the user is unable to clearly define their needs. And the analysis using Unified Modeling Language method used to perform specifications, visualization, construction, and documentation artifact a software system

Keywords: Android, physics, formula

\section{PENDAHULUAN}

Pada saat ini teknologi yang ada pada saat ini telah berkembang pesat. Dunia pendidikan juga harus mengalami kemajuan agar dapat membantu mahasiswa dalam menyerap ilmu yang diterima sehingga penggunaan teknologi diharapkan dapat membantu mahasiswa dalam memahami pelajaran yang diserapnya.

Kemudian ditemukan keluhan dari sebagian besar mahasiswa bahwa perkuliahan Fisika Dasar memiliki tingkat efektivitas yang rendah dan relevansinya pada dunia kerja tampak kurang, bahkan dinilai tidak terkait. Hal ini dikarenakan penyampaian materi tidak meninjau langsung permasalahan pada dunia industri itu sendiri, serta kurang menitikberatkan teori yang terkait dengan permasalahan yang nyata (Risti,2012)

Masalah yang sering dihadapi mahasiswa dalam pelajaran fisika adalah sulitnya memahami rumus-rumus yang ada begitu banyak, kesulitan menghafal rumus-rumus tersebut. Namun dapat dibantu dengan adanya beberapa situs yang menyediakan rumus-rumus fisika, tetapi membutuhkan koneksi internet dan harus diakses satu per satu serta rumus yang disediakan oleh situs tersebut kurang lengkap, selain itu terkadang situs tersebut tidak dilengkapi oleh latihan soal sehingga mahasiswa tidak dapat menerapkan fungsi rumus tersebut secara langsung. Maka dibutuhkan sebuah aplikasi yang dapat membantu mahasiswa membahas kasus dalam fisika dasar dengan berbantuan teknologi android.

Tujuan dari penelitian ini adalah :

- Untuk mengembangkan sebuah aplikasi yang interaktif dan dapat menarik minat mahasiswa untuk mempelajari fisika dasar.

- Untuk meningkatkan pemahaman mahasiswa tentang fisika dan mempermudah mahasiswa dalam mengerjakan tugas.

\section{METODOLOGI PENELITIAN}

\section{Metode Pengembangan Sistem}

Metode yang digunakan dalam penelitian ini adalah metode Prototype (Rapid Application Design/RAD). Model Prototipe (Prototype) sangat baik digunakan untuk menyelesaikan masalah kesalahpahaman antara user dan analis yang timbul akibat user tidak mampu mendefinisikan secara jelas kebutuhannya (Roger,2001). Prototyping adalah pengembangan yang cepat dan pengujian terhadap model kerja (prototype) dari aplikasi baru melalui proses interaksi dan berulang-ulang yang biasa digunakan ahli sistem informasi dan ahli bisnis, karena menyederhanakan dan mempercepat desain sistem. 


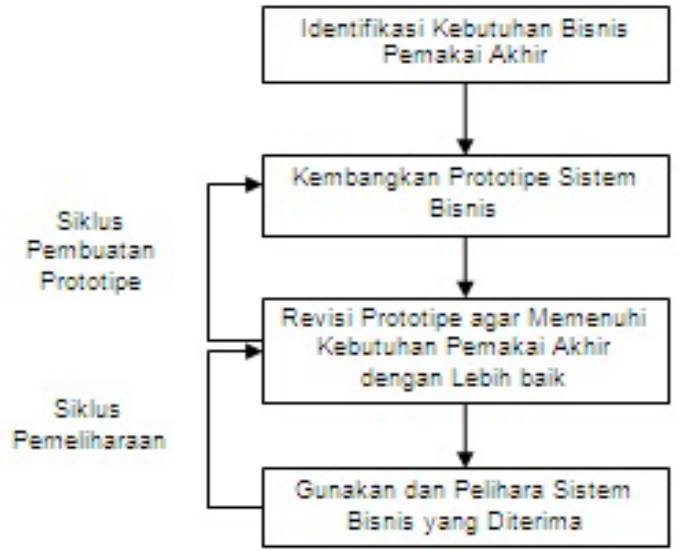

Gambar 1. Langkah-langkah prototype

\section{Alat Perancangan system}

Menggunakan Unified Modeling Language atau UML yang digunakan untuk melakukan spesifikasi, visualisasi, konstruksi, dan dokumentasi artifak sebuah sistem perangkat lunak. (Dennis, 2012)

UML merupakan metodologi kolaborasi antara metoda-metoda Booch, OMT (Object Modeling Technique), serta OOSE (Object Oriented Software Engineering) dan beberapa metoda lain merupakan metoda yang paling sering digunakan saat ini untuk mengadaptasi maraknya penggunaan Bahasa "Pemrograman Berorientasi Objek".

\section{HASIL DAN PEMBAHASAN}

Rancangan ini bertujuan untuk memudahkan mahasiswa untuk mempelajari dan memahami mata kuliah yang berkaitan dengan fisika dengan lebih efektif. yang berjalan dengan sistem operasi Android yang dirancang khusus untuk smartphone dan tablet, serta dapat dilakukan secara offline, sehingga pengguna tidak wajib terhubung pada internet untuk menggunakan aplikasi ini.

Pada tahap ini, perancangan aplikasi akan dibuat untuk mendeskripsikan aplikasi yang akan dibuat dengan menggunakan use case diagram, activity diagram, sequence diagram, class diagram, dan interface dari aplikasi.

\section{Perancangan Sistem}

- Use Case Diagram

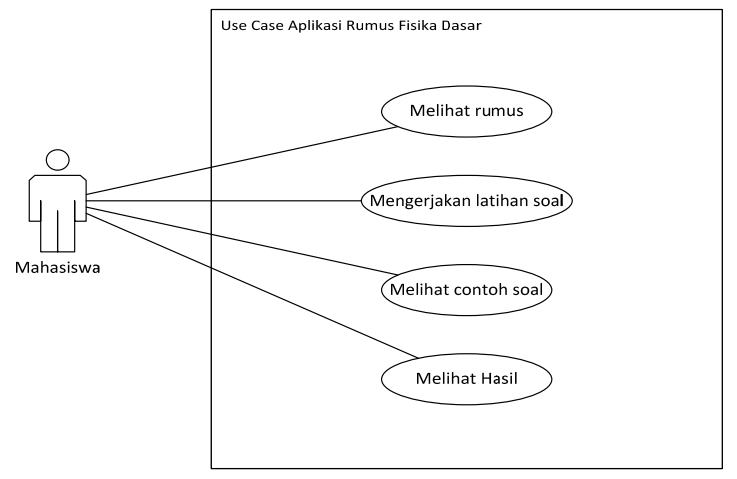

Gambar 2. Use Case Diagram Sistem Usulan
Dalam rancangan ini mahasiswa yang berperan sebagai user dapat melihat rumus, mengerjakan latihan dan contoh soal serta dapat melihat hasil setelah mengerjakan soal pada smartphone dan tablet.

- Activity Diagram

Untuk dapat melihat aktifitas yang lebih detail dalam rancang bangun fisika ini dapat dilihat pada table activity di bawah ini. Semua aktifitas di jelaskan secara mendetall pada gambar melihat rumus, mengerjakan soal, dan melihat hasil pengerjaan soal yang sudah disediakan di system.

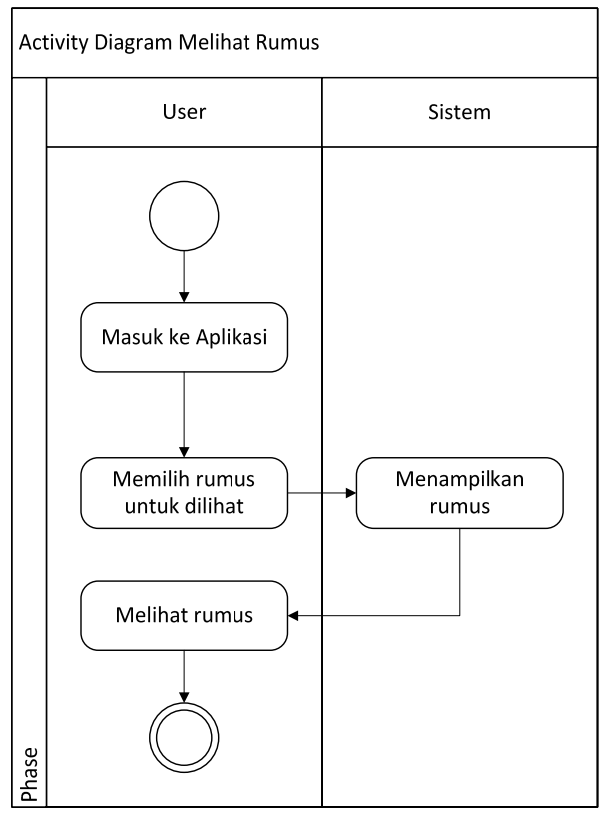

Gambar 3 Activity Diagram Melihat Rumus

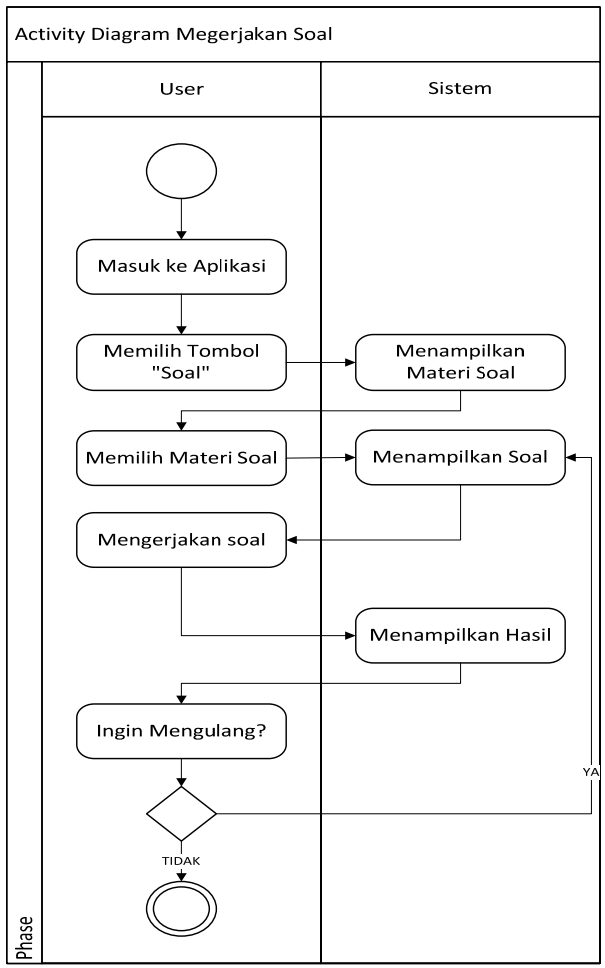

Gambar 4 Activity Diagram Mengerjakan Soal 


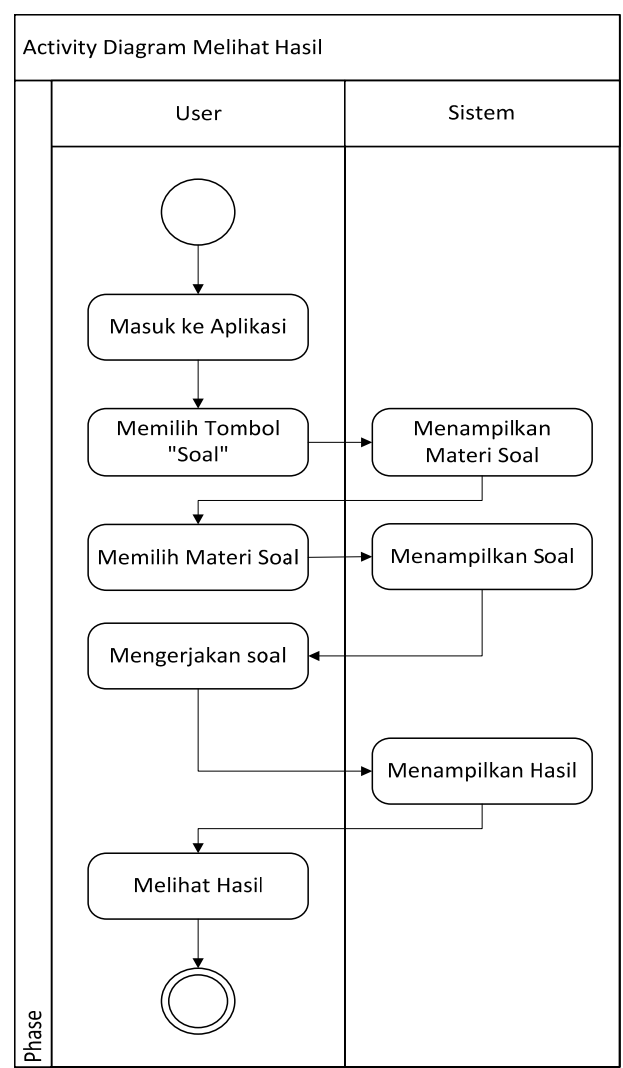

Gambar 5. Activity Diagram Melihat Hasil

\section{Implementasi}

Berikut adalah spesifikasi dari perangkat keras yang digunakan pada saat system ini dibuat.

1. Perangkat Keras

- Tipe Komputer : Laptop

- Prosesor : Intel Core i7-4720HQ CPU @ 2.60GHz

- RAM :8 GB

- HDD :1 TB

2. Perangkat Lunak

- System Operasi : Windows 10

- Server : SQLite

- Program : Android

\section{Antarmuka Halaman}

Antarmuka (User Interface) adalah tampilan menu pada sistem hingga tulisan, gambar, konten, dan bagian lain ynag dapat mendukung sebuah aplikasi agar dapat digunakan sebagaimana fungsinya.

Berikut adalah tampilan dari antarmuka sistemnya.

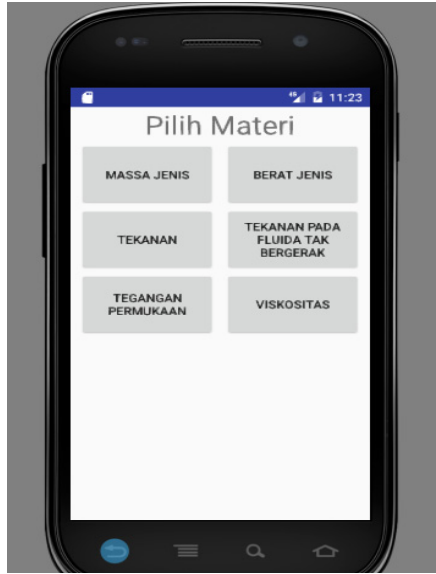

Gambar 6. Tampilan Antarmuka Pilihan Materi Rumus

Antarmuka ini menampilkan pilihan materi rumus yang dapat dijadikan informasi materi, seperti massa jenis, berat jenis, tekananm tekanan pada fluida tak bergerak, tegangan permukaan, viskositas, dan lain-lain.

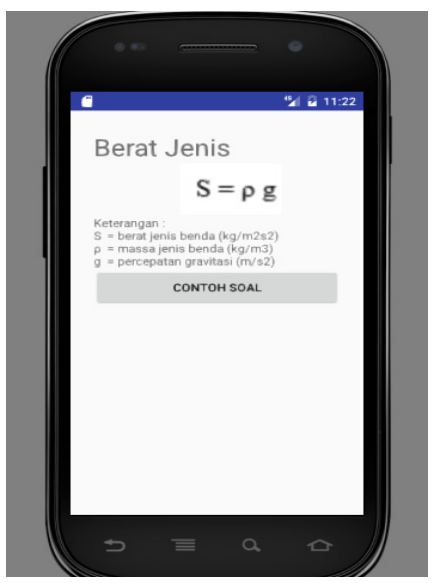

Gambar 7. Tampilan Antarmuka Rumus

Antarmuka ini menampilkan rumus yang telah dipilih pada sub bab yang telah dipilih sebelumnya. ni diantaranya ada Rumus FLuida, rumus gaya gravitasi, rumus perlajuan Jika memilih salah satu tombol ini maka akan terhubung pada antarmuka pilihan materi rumus.

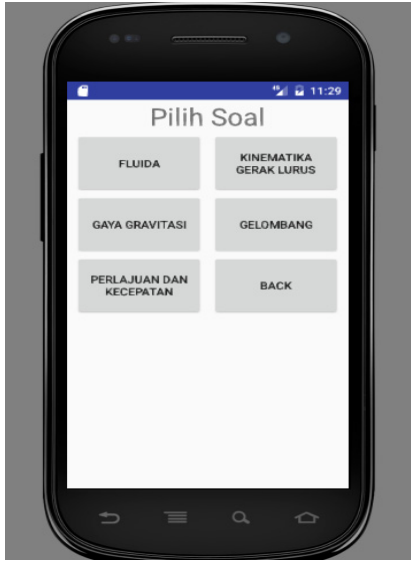

Gambar 8. Tampilan Antarmuka Pilihan Soal 
Antarmuka ini menampilkan bab-bab yang akan dikerjakan. Antarmuka ini dapat diakses dengan memilih tombol soal pada antarmuka menu utama. Jika memilih salah satu tombol pada antarmuka ini maka akan terhubung pada antarmuka soal.

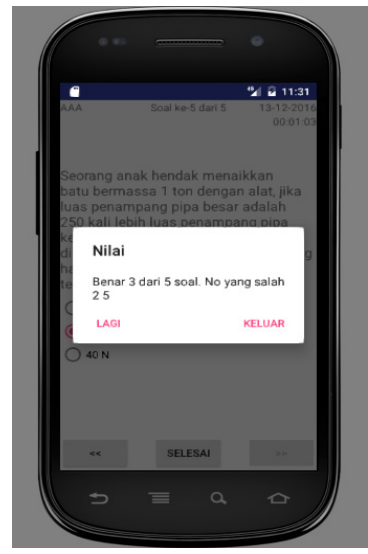

Gambar 9. Tampilan Antarmuka Hasi
Antarmuka ini adalah hasil dari pengerjaan soal sebelumnya. Antarmuka ini akan menampilkan jumlah soal yang benar dan akan nomor soal mana saja yang salah dikerjakan.

\section{Pengujian}

Pada tahapan ini, dilakukan pengujian terhadap aplikasi yang telah dibuat. Metode yang dilakukan dalam pengujian ini adalah metode pengujian Black Box, yaitu menguji aplikasi dari segi fungsionalitasnya. Skenario pengujian dilakukan dengan memilih setiap setiap pilihan yang ada pada aplikasi ini, kemudian dilakukan pengujian dengan menekan tombol-tombol pada layout aplikasi untuk mengetahui apakah aplikasi sudah berjalan sesuai dengan fungsinya.

Tabel 1. Tabel Skenario Pengujian

\begin{tabular}{|c|c|c|c|c|c|c|}
\hline No & Tampilan & Uji Coba & Status & $\begin{array}{c}\text { Skenario } \\
\text { Pengujian }\end{array}$ & $\begin{array}{l}\text { Hasil Yang } \\
\text { Diharapkan }\end{array}$ & Hasil Pengujian \\
\hline 1 & $\begin{array}{l}\text { Layout } \\
\text { Halaman } \\
\text { Utama }\end{array}$ & $\begin{array}{l}\text { Masuk Ke } \\
\text { Layout Pilihan } \\
\text { Rumus }\end{array}$ & $\begin{array}{l}\text { Membuka } \\
\text { Layout Pilihan } \\
\text { Rumus }\end{array}$ & $\begin{array}{l}\text { Memilih Tombol } \\
\text { Rumus }\end{array}$ & $\begin{array}{l}\text { Masuk Ke Layout } \\
\text { Pilihan Rumus }\end{array}$ & $\begin{array}{l}\text { Berhasil Masuk } \\
\text { Ke Layout } \\
\text { Pilihan Rumus }\end{array}$ \\
\hline 2 & $\begin{array}{l}\text { Layout } \\
\text { Halaman } \\
\text { Utama } \\
\end{array}$ & $\begin{array}{l}\text { Masuk Ke } \\
\text { Layout Pilihan } \\
\text { Soal }\end{array}$ & $\begin{array}{l}\text { Membuka } \\
\text { Layout Pilihan } \\
\text { Soal }\end{array}$ & $\begin{array}{l}\text { Memilih Tombol } \\
\text { Soal }\end{array}$ & $\begin{array}{l}\text { Masuk Ke Layout } \\
\text { Pilihan Soal }\end{array}$ & $\begin{array}{l}\text { Berhasil Masuk } \\
\text { Ke Layout } \\
\text { Pilihan Soal }\end{array}$ \\
\hline 3 & $\begin{array}{l}\text { Layout } \\
\text { Pilihan } \\
\text { Rumus }\end{array}$ & $\begin{array}{l}\text { Masuk Ke } \\
\text { Layout Pilihan } \\
\text { Materi }\end{array}$ & $\begin{array}{l}\text { Membuka } \\
\text { Layout Pilihan } \\
\text { Materi }\end{array}$ & $\begin{array}{l}\text { Memilih Salah } \\
\text { Satu Tombol } \\
\text { Pilihan Rumus }\end{array}$ & $\begin{array}{l}\text { Masuk Ke Layout } \\
\text { Pilihan Materi }\end{array}$ & $\begin{array}{l}\text { Berhasil Masuk } \\
\text { Ke Layout } \\
\text { Pilihan Materi }\end{array}$ \\
\hline 4 & $\begin{array}{l}\text { Layout } \\
\text { Pilihan } \\
\text { Materi }\end{array}$ & $\begin{array}{l}\text { Masuk Ke } \\
\text { Layout } \\
\text { Tampilan } \\
\text { Rumus } \\
\end{array}$ & $\begin{array}{l}\text { Membuka } \\
\text { Layout Tampilan } \\
\text { Rumus }\end{array}$ & $\begin{array}{l}\text { Memilih Salah } \\
\text { Satu Tombol } \\
\text { Materi Fisika }\end{array}$ & $\begin{array}{l}\text { Masuk Ke Layout } \\
\text { Tampilan Rumus }\end{array}$ & $\begin{array}{l}\text { Berhasil Masuk } \\
\text { Ke Layout } \\
\text { Pilihan Materi }\end{array}$ \\
\hline 5 & $\begin{array}{l}\text { Layout } \\
\text { Pilihan Soal }\end{array}$ & $\begin{array}{l}\text { Masuk Ke } \\
\text { Layout Soal }\end{array}$ & $\begin{array}{l}\text { Membuka } \\
\text { Layout Soal }\end{array}$ & $\begin{array}{l}\text { Memilih Salah } \\
\text { Satu Tombol } \\
\text { Pilihan Soal }\end{array}$ & $\begin{array}{l}\text { Masuk Ke Layout } \\
\text { Soal }\end{array}$ & $\begin{array}{l}\text { Berhasil Masuk } \\
\text { Ke Layout Soal }\end{array}$ \\
\hline 6 & Layout Soal & $\begin{array}{l}\text { Mengerjakan } \\
\text { Soal }\end{array}$ & $\begin{array}{l}\text { Menguji Hasil } \\
\text { Dari Pengerjaan } \\
\text { Soal }\end{array}$ & $\begin{array}{l}\text { Mengerjakan } \\
\text { Soal }\end{array}$ & $\begin{array}{l}\text { Menampilkan } \\
\text { Hasil Benar Dan } \\
\text { Salah }\end{array}$ & $\begin{array}{l}\text { Berhasil } \\
\text { Menampilkan } \\
\text { Hasil Benar Dan } \\
\text { Salah }\end{array}$ \\
\hline
\end{tabular}

\section{KESIMPULAN DAN SARAN}

Kesimpulan yang dapat diambil dalam penelitian ini adalah sebagai berikut:

1. Rancang bangun ini membantu mahasiswa dalam pemahaman rumus-rumus fisika dasar dan dapat mengaplikasikannya dengan disediakannya kasus-kasus yang sangat berkaitan

2. Rancang bangun ini dapat diaplikasikan pada smartphone dan tablet berbasis android dan dipakai secara offline, sehingga mahasiswa dapat menggunakannya pada waktu tak terbatas.

Beberapa saran yang dapat dijadikan beberapa bahan pertimbangan dalam pengembangan aplikasi ini, diantaranya adalah :
1. Sistem ini Berbasis Android sehingga dapat di upload di Play Store untuk mempermudah user untuk mendapatkan aplikasi ini.

2. Sistem ini dapat dikembangkan untuk ilmu fisika terapan, matematika, kimia, dan lain sebagainya.

\section{DAFTAR PUSTAKA}

Buku

Burnette, Ed.( 2010). Hello, Android. Texas: Pragmantic Programmers

Crowell, Benjamin. (2006). Conceptual Physics. California: Creative Commons

Dennis, Alan, Barbara Haley Wixom, dan Roberta M. Roth. (2012). System Analysis and Design. New Jersey: John Wiley \& Sons, Inc. 
Huda, Arif Akbarul.( 2013). Live Coding! 9 Aplikasi Android Buatan Sendiri. Yogyakarta: Andi.

Khan, Mohd. Ehmer. (2010). Different Forms of Software Testing Techniques for Finding Errors. Oman: IJCSI International Journal of Computer Science Issues.

Nugroho, Adi.( 2009). Rekayasa Perangkat Lunak Menggunakan UML dan JAVA. Yogyakarta: Andi.

Pressman, Roger S.( 2001). Software Engineering : A Practitioner's Approach, English Edition. New York: The McGraw-Hill Companies, Inc.

Rosyid, Muhammad Farchani, Eko Firmansyah, dan Yusuf Dyan Prabowo ( 2014). Fisika Dasar Jilid I : Mekanika. Yogyakarta: Penerbit Periuk.

Satzinger, John W., Robert B. Jackson, dan Stephen D. Burd.( 2012). System Analysis and Design in A Changing World. Boston: Course Technology Cengage Learning.

Walker, Jearl. (2011). Halliday \& Resnick Fundamental of Physics $9^{\text {th }}$ Edition. New Jersey: John Wiley \& Sons, Inc.

\section{Jurnal}

Risti Suryantari dan Flaviana, (2012). Pengajaran materi fisika dasar untuk mahasiswa Fakultas Teknologi Industri, Jurnal LPPM Univ Kristen Parahyangan. 